EPIDEMIOLOGY

\title{
Seroprevalence of and risk factors for HIV-1 infection among South American men who have sex with men
}

\author{
C T Bautista, J L Sanchez, S M Montano, V A Laguna-Torres, J R Lama, J L Sanchez, L Kusunoki, \\ H Manrique, J Acosta, O Montoya, A M Tambare, M M Avila, J Viñoles, N Aguayo, J G Olson, \\ J K Carr
}

Sex Transm Infect 2004;80:498-504. doi: 10.1136/sti.2004.013094

See end of article for authors' affiliations

Correspondence to: Christian T Bautista, US Military HIV Research Program and Henry $M$ Jackson Foundation, 1 Taft Court, Suite 250, Rockville, MD 20850, USA: cbautista@hivresearch.org

Accepted for publication 25 August 2004
Objectives: Sex among men constitutes an important route of transmission for HIV type 1 (HIV-1) in Latin America. Seeking better understanding of risk behaviours in this region, we determined the seroprevalence, potential risk factors, and geographic distribution of HIV-1 among groups of men who have sex with men (MSM).

Methods: Seroepidemiological, cross sectional studies of 13847 MSM were conducted in seven countries of South America during the years 1999-2002. Volunteers were recruited in city venues and streets where anonymous questionnaires and blood samples were obtained. HIV-1 infection was determined by enzyme linked immunosorbent assay (ELISA) screening and western blot (WB) confirmatory tests.

Results: HIV-1 seroprevalence varied widely (overall 12.3\%, range 11.0\%-20.6\%). The highest HIV-1 seroprevalence was noted in Bolivia (20.6\%) and the lowest in Peru (1 1.0\%). Predictors of HIV-1 infection varied among countries; however, a history of previous sexually transmitted disease (STD) was associated with a consistent increased risk (ORs $=1.9-2.9, A O R s=1.8-2.7)$. Multiple weekly sexual contacts was found to represent a secondary risk factor in Ecuador, Peru, and Argentina (ORs = 1.6-2.9, AORs = 1.63.1), whereas use of drugs such as cocaine was found to increase risk in Bolivia, Uruguay, and Paraguay (ORs = 2.5-6.5, AORs=2.6-6.1).

Conclusion: The results of this study illustrate an elevated HIV-1 seroprevalence among MSM participants from Andean countries. A previous STD history and multiple partners predicted HIV-1 infection in the seven countries of South America. In Southern Cone countries, HIV-1 infection was also associated with use of illegal drugs such as cocaine.
$\mathrm{T}$ he burden of infection HIV type l (HIV-1) continues to increase worldwide. ${ }^{12}$ Men who have sex with men (MSM) remain one of the core groups at highest risk of HIV-1 despite a significant decline in the rates of new infections in certain areas of the world. ${ }^{2}$ Sexually transmitted diseases (STDs), to include co-infections with other viral and bacterial agents, represent one of the most important predisposing factors among MSM communities. ${ }^{3}$

In Latin America, there are an estimated 1.2-2.1 million HIV-1 infected people ${ }^{4}$; concentrated epidemics among MSM who engage in unprotected sex account for a significant proportion of these infections. Other factors such as injecting drug use (IDU) and heterosexual transmission are of increasing importance, however. ${ }^{14}$ Moreover, it has recently been estimated that between $8-24 \%$ of MSM in capital cities of Latin America are infected with HIV-1, ${ }^{5}$ accounting for approximately $42 \%$ of the total cumulative AIDS cases. ${ }^{6}$ As a comparison, in the United States, MSM accounted for approximately $53 \%$ of all new infections by the year $2000 .^{7}$

Clearly, MSM comprise a heterogeneous community and bisexual men represent an important "bridging" core group for transmission to other populations such as heterosexually active women in many parts of the world. Recent studies conducted in the United States, Australia, and Europe have documented changes in risk taking behaviour among MSM. ${ }^{8}$ Changes in risk behaviours have led to a significant increase in new HIV infections, principally because of the increase in risk associated with STDs among MSM..$^{8-13}$ Thus, continued surveillance are necessary to improve and implement preventive efforts as well as a means to better identify behaviours that contribute to the spread of HIV and other STDs among MSM. ${ }^{13}$
HIV-1 prevalence estimates among MSM groups have been reported in only a few studies in South America. ${ }^{14-16}$ The data in this report, which include numerous MSM and FCSW (female commercial sex workers) cohorts, represent the largest cross sectional examination of HIV-1 prevalence conducted in South America to date, and include references to information which will be presented elsewhere by one of our collaborators (SMM). In a preliminary analysis among MSM communities, STDs and drug related risk factors were initially observed to be associated with HIV-1 infection. To seek a better understanding of risk behaviors, risk factors, and the geographic distribution of HIV-1 among MSM in this region, additional analyses were carried out in greater detail including country by country specific risk factors for HIV-l infection.

\section{METHODS}

Study population

A total of 19 seroepidemiological, cross sectional studies were conducted among varied MSM communities during the years 1999-2002 in 36 cities of seven different countries. Sites included Bogota in Colombia; Quito, Guayaquil, and four other port cities in Ecuador; Lima, Iquitos, Pucallpa, Trujillo, Arequipa, Tacna, and Sullana in Peru; La Paz y Santa Cruz in Bolivia; Asuncion, four other cities, and two border cities with Brazil and Argentina in Paraguay; Montevideo and four border cities with Brazil in Uruguay; and Buenos Aires and

Abbreviations: ELISA, enzyme linked immunosorbent assay; FCSW, female commercial sex workers; IDU, injecting drug use; MSM, men who have sex with men; STDs, sexually transmitted diseases; WB, western blot 
Table 1 HIV-1 seroprevalences among 13847 MSM participants from seven countries in South America, 1999-2002

\begin{tabular}{llll}
\hline Region/country & Period & $\%$ & (n/No*) \\
\hline $\begin{array}{c}\text { Total } \\
\text { Andean Region }\end{array}$ & $1999-2002$ & 12.3 & $(1700 / 13847)$ \\
Colombia & & 12.0 & $(1498 / 12517)$ \\
Ecuador & 2002 & 19.7 & $(130 / 660)$ \\
Peru & $1999-2002$ & 16.6 & $(105 / 632)$ \\
Bolivia & $1999-2000$ & 11.0 & $(1204 / 10939)$ \\
Southern Cone & $1999-2002$ & 20.6 & $(59 / 286)$ \\
Argentina & $2000-2002$ & 15.2 & $(202 / 1330)$ \\
Uruguay & $1999-2002$ & 14.5 & $(119 / 819)$ \\
Paraguay & 2002 & 16.9 & $(71 / 419)$ \\
\hline
\end{tabular}

HIV-1, human immunodeficiency virus type 1; MSM, men who have sex with men.

*In parentheses are the number of HIV positive ( $n$ )/total number participants tested (No).

seven other cities in Argentina. These cross sectional studies were conducted by researchers from the US Naval Medical Research Center Detachment, Lima, Peru (NMRCD-Lima), US Military HIV Research Program (USMHRP) at the Walter Reed Army Institute of Research (WRAIR), and the Henry M Jackson Foundation (HJF), Rockville, MD, in close collaboration and coordination with local country's ministry of health $(\mathrm{MoH})$, AIDS supporting non-governmental organisations (NGOs), and the Pan American Health Organization (PAHO) as described elsewhere. ${ }^{14}$

Study protocols were approved in advance by human use ethics and institutional review boards in each country as well as by the US Navy Medical Research Center (NMRC), Silver Spring, MD, USA. All MSM subjects were 18 years of age or older, agreed to participate in the study, and were enrolled after providing written informed consent in accordance with human use study guidelines. MSM participants were contacted at public and private venues and meeting locations (such as discos and bars) as well as in the street (in the case of male commercial sex workers in Montevideo, Uruguay). No records of potential versus actual participants were collected in these studies; therefore, no assessment of completeness and representativeness of MSM participation could be achieved. Baseline demographic and epidemiological data, which contained information regarding sexual and other risk behaviours were collected by trained staff with experience in HIV and STD prevention using a standardised questionnaire. Participants were also asked about their lifetime and length of use of drugs, including marijuana, cocaine, and heroin (either past or present). A venous blood sample was collected from each participant for HIV antibody testing as detailed below and as previously published. ${ }^{14}$ Participants received counselling on reducing STD infection risk, and were referred to appropriate medical and social services.

\section{Laboratory testing}

Details of laboratory testing have been described in detail elsewhere. ${ }^{14-16}$ Briefly, serum samples were tested for antibodies against HIV-1 by enzyme linked immunosorbent assay (ELISA) screening (Bio-Rad, Hercules, CA, USA), and repeatedly reactive samples were subjected to western blot (WB) confirmation using standardised FDA approved testing kits (Calypte Biomedical, Alameda, CA, USA).

\section{Statistical analysis}

HIV-l seroprevalences were expressed as percentage. $\chi^{2}$ and Fisher's exact test were utilised to compare differences in categorical variables. Mann-Whitney $U$ and Kruskal-Wallis $\mathrm{H}$, two non-parametric tests, were used to compare differences between continuous variables. Variables of interest in this initial analysis included age, number of sexual contacts per week (categorised as $0-1,2-3$, and 4 or more), STD history, sexual contact with foreigners, use of drugs in the present and past (marijuana, cocaine and/or heroin), injecting and non-injecting drug use, alcohol use, and history of previous blood transfusions.

To assess the type of drug used and mode, three separate categories were created in the database (no drug use as reference category, non-injecting, and injecting drug use). Age was categorised into quartiles to evaluate the presence of linear association of increasing HIV-1 seroprevalence with age. Two separate regions of South America were looked at in more detail, the Andean region consisting of Colombia, Ecuador, Peru, and Bolivia, and the Southern Cone region consisting of Argentina, Paraguay, and Uruguay. Odds ratios (OR) and adjusted ORs (AOR) controlling for age (years) and number of sexual contacts per week were estimated in univariate and multiple logistic regression analyses as well as associated $95 \%$ confidence intervals (95\% CI). Potential risk factors that were found to be significant in univariate analysis, or with a p value $<0.15$, were entered in a forward stepwise selection multivariate logistic regression model to identify independent risk factors associated with HIV-l infection. Goodness of fit was assessed by the HosmerLemeshow test. ${ }^{17}$ All reported probability $(\mathrm{p})$ values are two sided; $p$ values of $<0.05$ were considered to be statistically significant. All data analyses were performed using SPSS v.10

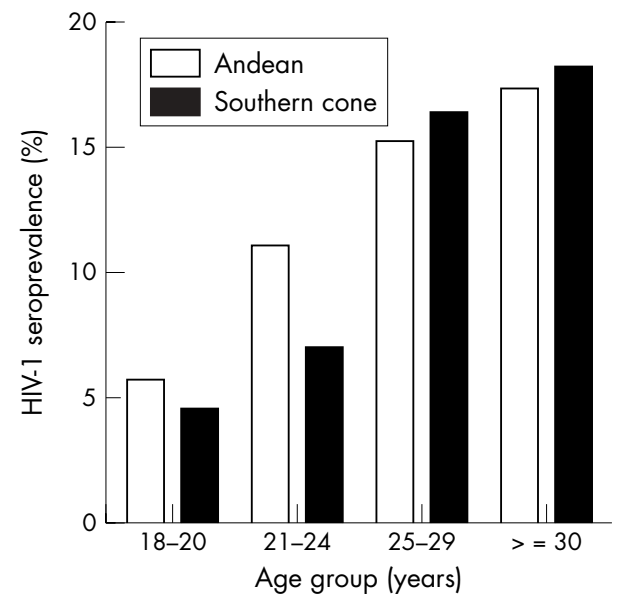

Figure 1 HIV-1 seroprevalences by region and age groups among 13847 MSM participants from seven countries in South America, 1999-2002. Note: Increasing of seroprevalences in both regions ( $p<0.05$ by $\chi^{2}$ for trend). 
(SPSS Corporation, Chicago, IL, USA) and SAS v.8.0 (SAS Institute, Cary, NC, USA).

\section{RESULTS}

A total of 13847 MSM participants were enrolled in this study between 1999-2002. Of these, 12517 (90.4\%) were enrolled in the Andean region and 1330 (9.6\%) in Southern Cone countries. Given their high level of involvement by $\mathrm{MoH}$ and NGOs in pre-existing collaborations with MSM based studies in the past, two countries accounted for over two thirds of the study sample; Peru which accounted for 10939 (87.4\%) participants in the Andean region, and Argentina which accounted for $819(61.6 \%)$ participants in the Southern Cone countries. In Peru, since 1996, the MoH has implemented biannual HIV and STD sentinel surveillance as a way to monitor the HIV epidemic among MSM. The median age of participants was 25.0 years (range 18-75), and a significant difference was found among countries with subjects from Argentina found to be older $(p<0.001)$. The overall median age of HIV positive subjects was 28.0 years (range 28-32). HIV positive subjects were found to be significantly older than HIV negative ones in Colombia, Ecuador, Peru, Bolivia, and Uruguay $(\mathrm{p}<0.05)$.

\section{HIV-1 prevalence analysis}

HIV-1 seroprevalence by country is shown in table 1 . The overall HIV-1 seroprevalence among all participants was $12.3 \%$ (range $11.0 \%-20.6 \%$ ). The highest seroprevalence was noted in Bolivia (20.6\%) and the lowest in Peru (11.0\%). HIV-1 seroprevalences were also found to be higher, on average, in the Southern Cone region when compared to the Andean region ( $15.2 \% \vee 12.0 \%$ respectively, $\mathrm{p}=0.001)$. A linear association of increasing HIV-1 seroprevalence with age (by quartile intervals, $\mathrm{p}<0.05$ by $\chi^{2}$ for trend) was found in both regions (fig 1). This linear association was also found by country, with the exception of Paraguay (table 2).

Comparison of HIV-l seroprevalence for each potential variable, in a country by country fashion, revealed significant differences (table 3). In general, the difference in HIV-1 seroprevalence was found with multiple sexual contacts (Ecuador, Peru, and Uruguay), for those with an STD history (all countries except Uruguay and Paraguay), for those who reported having had sex with foreigners (Peru, Bolivia, and Uruguay), for those who engaged in any kind of drug use (Bolivia and Uruguay), for those who consumed cocaine (Bolivia, Uruguay, and Paraguay), and for those who reported IDU behaviours (Bolivia and Uruguay). No significant differences in HIV-1 seroprevalence were observed for the very few individuals who reported using heroin $(\mathrm{n}=26)$, as well as for those who reported consistent alcohol use, or who gave a previous history of blood transfusion.

\section{Risk factor analysis}

Numerous potential risk factors were associated with HIV-1 infection in univariate and multiple analyses (adjusted for age and number of sexual contacts per week), and those found to be statistically significant are shown by country in table 4. A history of a previous STD was associated with a consistent increased risk in all countries, except Uruguay and Paraguay (ORs $=1.9-2.9$, AORs $=1.8-2.7)$. In addition, multiple weekly sexual contacts represented a secondary risk factor in Ecuador, Peru, and Argentina (ORs = 1.6-2.9, AORs $=1.6-3.1)$. By contrast, non-sexual risk behaviours, especially the use cocaine, increased the risk of infection in the countries of Bolivia, Uruguay, and Paraguay (ORs $=2.5-$ 6.5, AORs $=2.6-6.1$ ). Additionally, an IDU history increased the risk only in the countries of Bolivia and Uruguay $(\mathrm{ORs}=2.6-3.2$, AORs $=2.7-2.8)$. Sexual contact with foreigners was also associated with HIV-1 infection in Peru, Bolivia, and Uruguay (ORs $=2.1-2.4$, AORs $=2.1-2.2$ ). Age (years) was also to be associated with HIV-1 infection in Andean region $(\mathrm{OR}=1.04,95 \% \mathrm{CI}=1.03$ to $1.05, \mathrm{p}<0.001)$ as well as in the Southern Cone $(\mathrm{OR}=1.02,95 \% \mathrm{CI}=1.00$ to $1.04, \mathrm{p}=0.036$ ).

All significant associations found in the univariate analyses essentially remained in the multiple analysis with the caveat that two additional potential risk factors were also associated with HIV-I infection in multiple analyses-use of marijuana in Bolivia $(\mathrm{AOR}=1.98,95 \% \mathrm{CI}=1.19$ to $3.30, \mathrm{p}=0.009)$ and having two or three sexual contacts per week in Argentina $(\mathrm{AOR}=2.01,95 \% \mathrm{CI}=1.10$ to 3.67, $\mathrm{p}=0.023)$.

Evaluation of risk factors by multivariate logistic regression analysis using a forward stepwise selection process is illustrated by country in table 5 . Independent predictors of HIV-1 infection varied among countries. A previous STD history remained independently associated with HIV-1 infection in the Andean region (ORs $=1.8-2.4)$, and in Argentina $(\mathrm{OR}=1.9)$. An increased number of sexual contacts per week was also found to be an independent predictor of HIV-1 infection in Ecuador $(\mathrm{OR}=2.1)$, Peru $(\mathrm{OR}=1.5)$, and Argentina $(\mathrm{OR}=1.9)$. Sexual contact with foreigners was an important factor only in Peru $(\mathrm{OR}=2.0)$ and Uruguay $(\mathrm{OR}=2.1)$. An IDU history was associated with an increased risk in Bolivia $(\mathrm{OR}=2.3)$ and Uruguay $(\mathrm{OR}=3.4)$, whereas non-injecting drug use and use of cocaine were only found to be an important factor predicting HIV-l infection in Uruguay $(\mathrm{OR}=7.4)$ and in Paraguay $(\mathrm{OR}=6.5)$, respectively.

Table 2 HIV-1 seroprevalences by country and age groups (years) among 13847 MSM participants from seven countries in South America, 1999-2002

\begin{tabular}{|c|c|c|c|c|c|c|c|c|c|}
\hline \multirow[b]{2}{*}{ Region/age groups } & \multicolumn{2}{|c|}{$18-20$ years } & \multicolumn{2}{|c|}{$21-24$ years } & \multicolumn{2}{|c|}{ 25-29 years } & \multicolumn{2}{|c|}{$\geqslant 30$ years } & \multirow[b]{2}{*}{ p Value* } \\
\hline & $\%$ & (n/No) & $\%$ & (n/No) & $\%$ & (n/No) & $\%$ & (n/No) & \\
\hline \multicolumn{10}{|l|}{ Andean Region } \\
\hline Colombia & 13.9 & $(11 / 79)$ & 16.2 & $(24 / 148)$ & 17.6 & $(29 / 165)$ & 24.5 & $(57 / 233)$ & 0.015 \\
\hline Ecuador & 11.1 & $(14 / 126)$ & 11.9 & $(20 / 168)$ & 23.2 & $(29 / 125)$ & 20.4 & $(41 / 201)$ & 0.005 \\
\hline Peru & 5.0 & $(120 / 2410)$ & 10.4 & $(284 / 2727)$ & 14.6 & $(334 / 2295)$ & 16.0 & $(415 / 2586)$ & $<0.001$ \\
\hline Bolivia & 11.6 & $(8 / 69)$ & 19.6 & $(19 / 97)$ & 18.0 & $(11 / 61)$ & 35.6 & $(21 / 59)$ & 0.002 \\
\hline \multicolumn{10}{|l|}{ Southern Cone } \\
\hline Argentina & 1.7 & $(1 / 60)$ & 5.7 & $(9 / 157)$ & 14.8 & $(30 / 203)$ & 16.0 & $(60 / 376)$ & $<0.001$ \\
\hline Uruguay & 4.7 & $(3 / 64)$ & 8.0 & $(6 / 75)$ & 20.2 & $(18 / 89)$ & 22.6 & $(43 / 190)$ & $<0.001$ \\
\hline Paraguay & 11.1 & $(3 / 27)$ & 11.1 & $(3 / 27)$ & 13.0 & $(3 / 20)$ & 20.0 & $(3 / 15)$ & 0.471 \\
\hline
\end{tabular}

HIV-1, human immunodeficiency virus type 1; MSM, men who have sex with men. In parentheses are number of HIV positive (n)/total number participants tested (No). Denominator totals varied slightly because of missing data. *By $\chi^{2}$ for trend. 


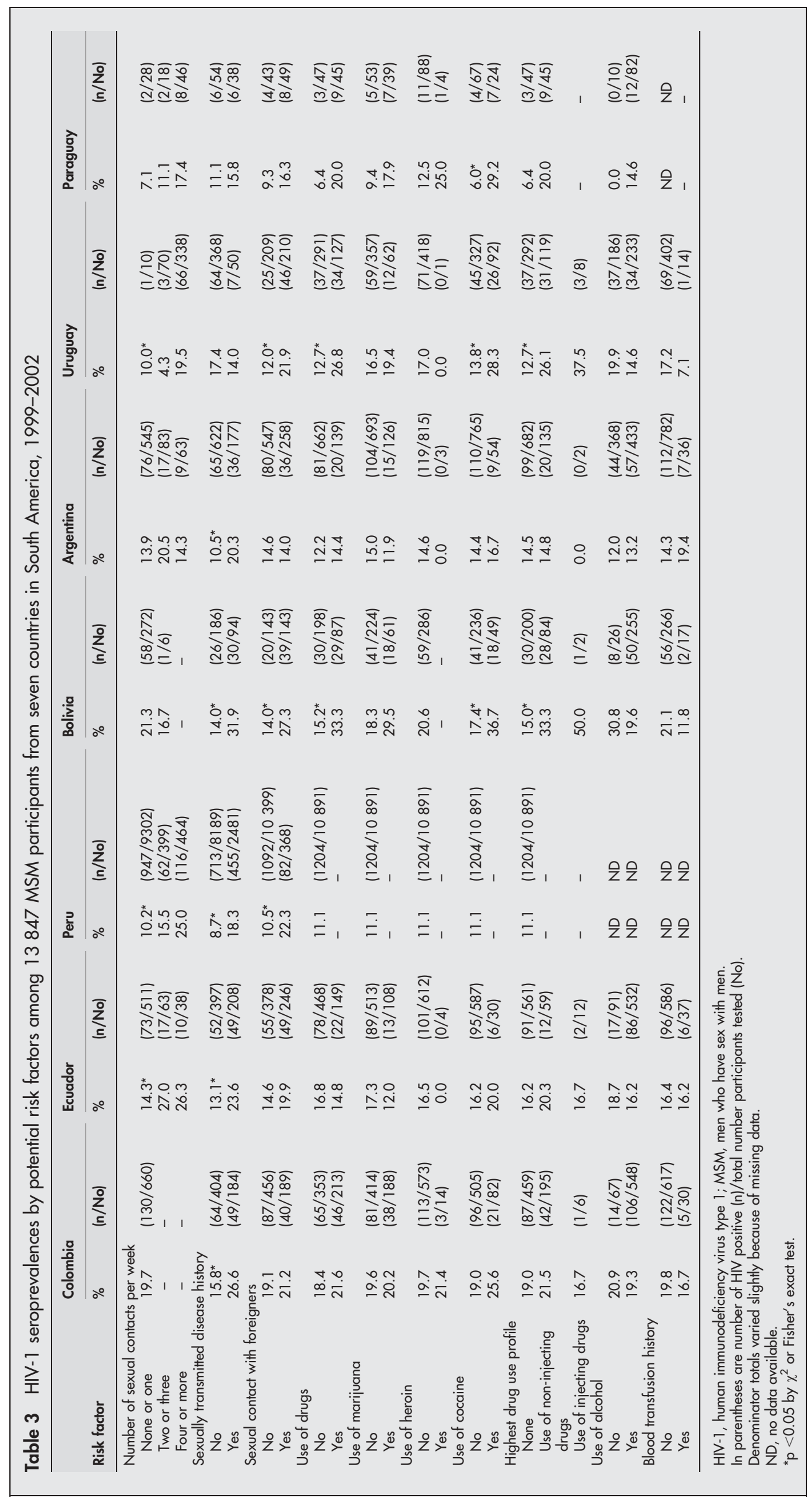


Table 4 Logistic regression analysis of risk factors associated with HIV-1 seropositivity among 13847 MSM participants from seven countries in South America, 1999-2002

\begin{tabular}{|c|c|c|c|c|c|c|}
\hline \multirow[b]{2}{*}{ Country/risk factor } & \multicolumn{3}{|c|}{ Univariate analysis } & \multicolumn{3}{|c|}{ Multiple analysis } \\
\hline & OR & $(95 \% \mathrm{Cl})$ & p Value & AOR & $95 \% \mathrm{Cl}$ & p Value \\
\hline \multicolumn{7}{|l|}{$\begin{array}{l}\text { Andean Region } \\
\text { Colombia }\end{array}$} \\
\hline $\begin{array}{l}\text { STD history (no) } \\
\text { Ecuador }\end{array}$ & 1.93 & (1.26 to 2.94$)$ & 0.002 & 1.79 & 1.13 to 2.83 & 0.013 \\
\hline Two or three sexual contacts per week (none or one) & 2.22 & (1.21 to 4.08$)$ & 0.010 & 2.20 & 1.17 to 4.12 & 0.014 \\
\hline Four or more sexual contacts per week (none or one) & 2.14 & $(1.00$ to 4.60$)$ & 0.050 & 2.31 & 1.07 to 5.00 & 0.033 \\
\hline STD history (no) & 2.05 & $(1.33$ to 3.15$)$ & 0.001 & 1.79 & 1.13 to 2.81 & 0.012 \\
\hline \multicolumn{7}{|l|}{ Peru } \\
\hline Four or more sexual contacts per week (none or one) & 2.94 & $(2.36$ to 3.67$)$ & $<0.001$ & 3.05 & 2.44 to 3.83 & $<0.001$ \\
\hline Sexual contact with foreigners (no) & 2.44 & $(1.90$ to 3.15$)$ & $<0.001$ & 2.08 & 1.59 to 2.72 & $<0.001$ \\
\hline STD history (no) & 2.36 & (2.07 to 2.68$)$ & $<0.001$ & 2.33 & 2.04 to 2.67 & $<0.001$ \\
\hline $\begin{array}{l}\text { Two or three sexual contacts per week (none or one) } \\
\text { Bolivia }\end{array}$ & 1.62 & (1.23 to 2.15 ) & 0.001 & 1.58 & 1.18 to 2.10 & 0.002 \\
\hline STD history (no) & 2.89 & $(1.58$ to 5.26$)$ & 0.001 & 2.69 & 1.45 to 5.00 & 0.002 \\
\hline Use of drugs (no) & 2.80 & (1.55 to 5.06$)$ & 0.001 & 2.95 & 1.60 to 5.45 & 0.001 \\
\hline Use of cocaine (no) & 2.76 & $(1.41$ to 5.40$)$ & 0.003 & 2.64 & 1.32 to 5.29 & 0.006 \\
\hline Use of injecting drugs (none) & 2.57 & (1.41 to 4.69$)$ & 0.002 & 2.68 & 1.43 to 4.99 & 0.002 \\
\hline Sexual contact with foreigners (no) & 2.31 & $(1.27$ to 4.20$)$ & 0.006 & 2.17 & 1.18 to 4.02 & 0.013 \\
\hline Use of marijuana (no) & 1.87 & $(0.98$ to 3.57$)$ & 0.058 & 1.98 & 1.19 to 3.30 & 0.009 \\
\hline \multicolumn{7}{|l|}{ Southern Cone } \\
\hline \multicolumn{7}{|l|}{ Argentina } \\
\hline STD history (no) & 2.19 & (1.40 to 3.42$)$ & 0.001 & 1.92 & 1.15 to 3.20 & 0.013 \\
\hline Two or three sexual contacts per week (none or one) & 1.59 & $(0.89$ to 2.86$)$ & 0.121 & 2.01 & 1.10 to 3.67 & 0.023 \\
\hline \multicolumn{7}{|l|}{ Uruguay } \\
\hline Use of non-injecting drugs (none) & 6.83 & (1.47 to 31.85$)$ & 0.014 & 8.48 & 1.63 to 43.99 & 0.011 \\
\hline Use of injecting drugs (none) & 3.21 & $(1.69$ to 6.10$)$ & $<0.001$ & 2.79 & 1.39 to 5.61 & 0.004 \\
\hline Use of drugs (no) & 2.51 & (1.49 to 4.23 ) & 0.001 & 2.78 & 1.59 to 4.86 & $<0.001$ \\
\hline Use of cocaine (no) & 2.47 & (1.42 to 4.29$)$ & 0.001 & 2.67 & 1.49 to 4.78 & 0.001 \\
\hline Sexual contact with foreigners (no) & 2.06 & (1.21 to 3.51$)$ & 0.007 & 2.19 & 1.25 to 3.85 & 0.006 \\
\hline \multicolumn{7}{|l|}{ Paraguay } \\
\hline Use of cocaine (no) & 6.48 & (1.70 to 24.75$)$ & 0.002 & 6.14 & 1.50 to 25.14 & 0.012 \\
\hline
\end{tabular}

\section{DISCUSSION}

To our knowledge, this study represents the largest cross sectional epidemiological study of HIV-l among MSM communities in Latin America. Our results suggest a high
HIV-1 seroprevalence in all seven countries (overall $12.3 \%$, range $=11.0 \%-20.6 \%)$, and especially in urban centres of the region (overall $14.6 \%$, range $=12.5 \%-23.2 \%$ ). Previously published, population based, HIV seroprevalence studies

Table 5 Potential risk factors found by multivariate logistic regression analysis using a forward stepwise selection process associated with HIV-1 seropositivity among 13847 MSM participants from seven countries in South America, 1999-2002

\begin{tabular}{|c|c|c|c|}
\hline Country/risk factor & OR & $95 \% \mathrm{Cl}$ & $\mathrm{p}$ Value \\
\hline \multicolumn{4}{|l|}{$\begin{array}{l}\text { Andean Region } \\
\text { Colombia }\end{array}$} \\
\hline $\begin{array}{l}\text { STD history (no) } \\
\text { Ecuador }\end{array}$ & 1.79 & 1.13 to 2.83 & 0.013 \\
\hline Two or three sexual contacts per week (none or one) & 2.12 & 1.12 to 4.02 & 0.020 \\
\hline STD history (no) & 1.79 & 1.13 to 2.81 & 0.012 \\
\hline \multicolumn{4}{|l|}{ Peru } \\
\hline Four or more sexual contacts per week (none or one) & 2.94 & 2.36 to 3.67 & $<0.001$ \\
\hline STD history (no) & 2.32 & 2.03 to 2.66 & $<0.001$ \\
\hline Sexual contact with foreigners (no) & 2.03 & 1.54 to 2.67 & $<0.001$ \\
\hline $\begin{array}{l}\text { Two or three sexual contacts per week (none or one) } \\
\text { Bolivia }\end{array}$ & 1.54 & 1.15 to 2.06 & 0.004 \\
\hline STD history (no) & 2.43 & 1.29 to 4.55 & 0.006 \\
\hline Use of injecting drugs (none) & 2.34 & 1.23 to 4.45 & 0.010 \\
\hline \multicolumn{4}{|l|}{ Southern Cone } \\
\hline \multicolumn{4}{|l|}{ Argentina } \\
\hline STD history (no) & 1.92 & 1.15 to 3.20 & 0.013 \\
\hline Two or three sexual contacts per week (none or one) & 1.85 & (1.01 to 3.42 & 0.048 \\
\hline \multicolumn{4}{|l|}{ Uruguay } \\
\hline Use of non-injecting drugs (none) & 7.42 & 1.50 to 36.65 & 0.014 \\
\hline Use of injecting drugs (none) & 3.38 & $(1.71$ to 6.67 & $<0.001$ \\
\hline Sexual contact with foreigners (no) & 2.06 & 1.18 to 3.60 & 0.011 \\
\hline \multicolumn{4}{|l|}{ Paraguay } \\
\hline Use of cocaine (no) & 6.49 & 1.70 to 24.77 & 0.005 \\
\hline
\end{tabular}




\section{Key messages}

- Seroepidemiological surveys of 13847 MSM were conducted in seven countries of South America during the years 1999-2002

- The overall HIV-1 seroprevalence was $12.3 \%$ (range $11.0 \%-20.6 \%)$. The highest seroprevalence was noted in Bolivia (20.6\%) and the lowest in Peru (11.0\%)

- History of previous STDs, multiple weekly sexual contacts, and use of drugs were found to increase risk of HIV-1 infection

among MSM communities in the western hemisphere have also reported similarly elevated seroprevalences in the United States (range of $15 \%-18 \%$ ) in 1997-9, ${ }^{818} 19$ Brazil (24\%) in $1994-8,{ }^{20}$ and in the Dominican Republic $(11 \%)$ in $1996 .{ }^{21}$ Estimates for the whole region of South America, however, also vary widely. Recent UNAIDS data just released in June $2004,{ }^{5}$ estimate HIV seroprevalences in capital cities to be as low as $8.2 \%$ in Honduras in 2002 and as high as $24.3 \%$ in Argentina in 2001 and $22.0 \%$ in Peru in 2002. By comparison, previously published data among similar groups in nine countries of the region also provide seroprevalences as low as $2.6 \%$ in Uruguay in 1996 and as high as 30.8 in Venezuela in $1992 .^{22}$ Thus, it is apparent that the epidemic in most countries of this region is still concentrated among MSM communities and, in some cases, in injecting drug users. ${ }^{23} 24$

In this study, Uruguay (16.9\%) reported the highest HIV-1 seroprevalence in the Southern Cone region. This elevated HIV-1 seroprevalence may be explained because MSM participants from Uruguay were male commercial sex workers. However, the HIV-l seroprevalence of this high risk core group was found not to be significantly different from that found for MSM in Argentina (14.5\%, p = 0.266) or Paraguay (13.0\%, p $=0.446)$.

Different potential risk factors associated with HIV-1 infection have been found and varied among countries. However, above all other factors, an STD history appears to constitute a common risk factor associated with HIV-1 infection in the whole region of South America. This is very concerning since increases in HIV prevalence among MSM communities in the United States and elsewhere have been recently described in association with viral and bacterial STDs. ${ }^{3-132526}$ Clearly, a renewed effort in prevention of STDs and understanding predisposing behavioural and sexual health risk practices is necessary in order to try to stem the tide of the HIV epidemic among MSM communities in this region. We were unable to evaluate the association between HIV-1 seropositivity and condom use given a high number of non-responders when country specific analyses was performed. However, after pooled analysis by region was performed (for example, Andean and Southern Cone region analyses separately), no significant association between condom use and HIV-1 infection was found after controlling by age and number of sexual contacts per week.

A geographic difference in patterns of use of non-injecting and injecting drugs has also been observed in our analyses. MSM from the Andean region, except for those in Bolivia, were less likely than MSM from Uruguay or Paraguay to report use of drugs. Our data seem to suggest that, in countries where harm reduction programmes against illegal drug use are being implemented, it will be necessary to ensure that such interventions are sustained, especially as they relate to making sure such public health measures are targeted towards the very high risk population of IDUs. ${ }^{27}$
We recognise that these cross sectional studies have some inherent limitations because of potential non-representativeness of the study population as well as the inherent difficulties associated with identifying and recruiting "stigmatised" members. Therefore, the findings of this study may be biased and may not accurately represent the true situation among MSM communities across the region. Despite these limitations, it is noteworthy to mention that all study participants were asymptomatic at time of enrolment and had not had a previously documented HIV-1 test in the past. Thus, we strongly think that we could estimate actual HIV-1 seroprevalences and associated risks in a reliable manner, without the real possibility of including previously documented HIV infected individuals in our study sample.

In conclusion, a previous STD history and exposure to multiple partners are known to be important determinants associated with HIV infection among MSM in most countries of South America (all except Uruguay and Paraguay). By contrast, use of illegal drugs, such cocaine, also appears to play an important part among MSM, especially in the Southern Cone countries of Uruguay and Paraguay. Effective, public health oriented, local educational and intervention programmes must be tailored in this high risk group vulnerable to HIV infection in each country according to the local prevailing sexual and social behavioural risk patterns.

\section{ACKNOWLEDGEMENTS}

We acknowledge the useful comments and suggestions of Warren B Sateren of the US Military HIV Research Program (USMHRP). We would like to acknowledge the assistance provided by Juan Perez, Pamela Limo, Claudia Oroya, and Ruth Centeno in data management; Gloria Chauca, Gladys Carrion, Maria Ester Gamero, and Merly Sovero in sample processing; and Gloria Talledo in administrative assistance at NMRCD-Lima. Finally, we are indebted to all of the MSM groups and communities in each country for their participation and contribution to the better understanding of the HIV-1 epidemic and to the many staff and scientists at the HIV/AIDS control programmes in each country for their tireless efforts in continuing to try to improve public health in this region.

\section{CONTRIBUTORS}

CTB and JLS conceived the idea for this manuscript, generated the initial working draft, conducted statistical analyses of the data and coordinated collaborators' responses; JRL, JLS, LK, and HM participated in the Peruvian study design, implementation, and data collection, as well as coordinated study protocol approval in Peru, and commented on initial manuscript draft and reviewer comments; JA, AM, AMT, MMA, JV, and NA participated in the design, implementation, and data collection in their respective countries in South America; JLS, VAL-T, SMM, and JKC participated in the design, approval, and implementation of all study protocols; all authors listed were involved in the interpretation of the results of the different studies, as well as in the review and approval of the final version of this manuscript.

\section{Authors' affiliations}

C T Bautista, J L Sanchez, J K Carr, US Military HIV Research Program and Henry M. Jackson Foundation, Rockville, MD, USA

S M Montano, V A Laguna-Torres, J G Olson, US Naval Medical Research Center Detachment-Lima, Peru

J R Lama, J L Sanchez, L Kusunoki, Asociación Civil Impacta Salud y Educación, Lima, Peru

A M Tambare, Centro Nacional de Enfermedades Tropicales (CENETROP), Programa ITS-SIDA, Santa Cruz, Bolivia

J Acosta, Instituto Nacional de Salud, Bogota, Colombia

O Montoya, Fundación Ecuatoriana Equidad, Quito, Ecuador

M M Avila, Centro Nacional de Referencia de SIDA (CNRS),

Universidad de Buenos Aires, Buenos Aires, Argentina

J Viñoles, Programa Nacional de Prevención y Control del VIH/SIDA, Ministerio de Salud, Montevideo, Uruguay

N Aguayo, Programa Nacional de Prevención y Control del VIH/SIDA, Ministerio de Salud, Asunción, Paraguay 
H Manrique, Programa Nacional de Control de ETS y SIDA (PROCETTS), Ministerio de Salud, Lima, Peru

Financial support: This study was supported by the US Military HIV Research Program (USMHRP) at the Walter Reed Army Institute of Research (WRAIR), and by the US Naval Medical Research Center (NMRC), Silver Spring, MD, USA. Work Unit Number (WUN) No 62787A S17 H B0002.

Disclaimer: The opinions and assertions made by the authors do not reflect the official position or opinion of the US Department of the Army or Navy, of the Henry M. Jackson Foundation for the Advancement of Military Medicine, or of the respective in-country national HIV/AIDS control programmes or non-governmental organisations (NGOs).

Human use statement: The study protocol was approved by the Naval Medical Research Center Institutional Review Board under Protocol \# NMRCD.2000.0002 (DoD 31523), Protocol \# NMRCD.1999.0002 (DoD 30590 and DoD 30583), Protocol \# NMRCD.1999.0001 (DoD 30587), Protocol \# NMRCD.2002.0006 (DoD 31590), and Protocol \# NMRCD.1998.0001 (DoD 30578), in compliance with all federal regulations governing the protection of human subjects.

Partial results of this study were previously presented at the AIDS Vaccine 2003 Meeting, New York, 20 September 2003 (Abstract No 478).

\section{REFERENCES}

1 World Health Organization, UNAIDS, 2003. Global summary of the HIV/ AIDS epidemic (available at www.otecaweb.com/pdf_notes/hiv_stats, last accessed on 20 March 2004).

2 Grant AD, De Cock KM. The growing challenge of HIV/AIDS in developing countries. Br Med Bull 1998;54:369-81.

3 Centers for Disease Control and Prevention. Resurgent bacterial sexually transmitted diseases among men who have sex with men. King County, Washington, 1997-1999. Morb Mort Wkly Rep 1999:48:773-7.

4 World Health Organization, UNAIDS, June 2004. Report on the global AIDS epidemic, 4th global report (available at www.unaids.org, last accessed on 30 July 2004)

5 World Health Organization, UNAIDS, June 2004. Report on the global AIDS epidemic, 4th global report, table of country-specific HIV/AIDS estimates and data, end 2003:189-207.

6 Pan American Health Organization. AIDS Surveillance in the Americas. Biannual Report, May 2000

7 Centers for Disease Control and Prevention. HIV/AIDS Surveillance Report. Morb Mort Wkly Rep 2000;12.

8 Centers for Disease Control and Prevention. Consultation on recent trends in STD and HIV morbidity and risk behaviors among MSM. Atlanta, GA. October 30-31, 2000. Meeting Report.

9 Wolitski RJ, Valdiserri RO, Denning PH, et al. Are we headed for a resurgence of the HIV epidemic among men who have sex with men? Am J Public Health $2001 ; 91: 883-8$

10 Valleroy L, Secura G, MacKellar D, et al, and the Young Men's Survey Study Group. High HIV and risk behavior prevalence among 23-39 year old men who have sex with men in 6 US cities. Abstract No 211, 8th Conference on Retroviruses and Opportunistic Infections. Chicago: IL, 5 February 2001.

11 Van De Ven P, Rawstorne P, Crawford J, et al. Increasing proportions of Australian gay and homosexually active men engage in unprotected anal intercourse with regular and with casual partners. AIDS Care 2002; 14:335-41.

12 Copas AJ, Wellings K, Erens B, et al. The accuracy of reported sensitive sexual behaviour in Britain: exploring the extent of change 1990-2000. Sex Transm Infect 2002;78:26-30.

13 Centers for Disease Control and Prevention. Increases in HIV diagnoses - 29 States, 1999-2002. Morb Mort Wkly Rep 2003;52:1145-8.

14 Hierholzer J, Montano S, Hoelscher M, et al. Molecular epidemiology of HIV type 1 in Ecuador, Peru, Bolivia, Uruguay, and Argentina. AIDS Res Hum Retrovir 2002; 18:1339-50.

15 Russi JC, Serra M, Vinoles J, et al. Sexual transmission of hepatitis B virus, hepatitis $C$ virus, and human immunodeficiency virus type 1 infections among male transvestite commercial sex workers in Montevideo, Uruguay. Am J Trop Med Hyg 2003;68:716-20.

16 Pando MA, Maulen S, Weissenbacher M, et al. High human immunodeficiency virus type 1 seroprevalence in men who have sex with men in Buenos Aires, Argentina: risk factors for infection. Int J Epidemiol 2003;32:735-40

17 Lemeshow S, Hosmer DW. A review of goodness of fit statistics for use in the development of logistic regression models. Am J Epidemiol 1982;115:92-106.

18 Catania JA, Osmond D, Stall RD, et al. The continuing HIV epidemic among men who have sex with men. Am J Public Health 2001;91:907-14.

19 Torian LV, Makki HA, Menzies IB, et al. HIV infection in men who have sex with men, New York City Department of Health sexually transmitted disease clinics, 1990-1999: a decade of serosurveillance finds that racial disparities and associations between HIV and gonorrhea persist. Sex Transm Dis 2002;29:73-8.

20 Sutmoller F, Penna TL, de Souza CT, et al, and the Oswaldo Cruz Foundation STD/HIV Prevention Group. Human immunodeficiency virus incidence and risk behavior in the 'Projeto Rio': results of the first 5 years of the Rio de Janeiro open cohort of homosexual and bisexual men, 1994-98. Int J Infect Dis 2002;6:259-65

21 Tabet SR, de Moya EA, Holmes KK, et al. Sexual behaviors and risk factors for HIV infection among men who have sex with men in the Dominican Republic. AIDS 1996;10:201-6.

22 Caceres CF. HIV among gay and other men who have sex with men in Latin America and the Caribbean: a hidden epidemic? AIDS 2002; 16:S23-33.

23 UNAIDS, WHO, Pan American Health Organization (PAHO). HIV and AIDS in the America: an epidemic with many faces. UNAIDS, WHO, Pan American Health Organization (PAHO), January 2001.

24 UNAIDS, AIDS Epidemic Update, December 2001. Geneva: UNAIDS, 2001.

25 Blackard JT, Mayer KH. HIV Superinfection in the era of increased sexual risktaking. Sex Transm Dis 2004;31:201-4

26 Valleroy LA, MacKellar DA, Karon JM, et al. HIV prevalence and associated risks in young men who have sex with men. Young Men's Survey Study Group. JAMA 2000;284:198-204.

27 Rodriguez CM, Marques LF, Touze G. HIV and injection drug use in Latin America. AIDS 2002;16:S34-41. 